may be obvious physical causes, such as pain and physical illness, for most other sufferers (especially Green) insomnia is more a problem of wakefulness intruding into sleep, rather than just bad sleep. To be more explicit, it is a 24-hour disorder in which persistent anxiety, anger or miserable notions, sitting constantly at the back of a person's mind, ruin the expectations of their next sleep. Clearly, the eventual cure must address this state of waking mind. It is pointless going to bed with these stresses.

Despite the author's fears, insomnia by itself in an otherwise healthy person is unlikely to cause depression or mental illness, unless these are quietly developing for other reasons. Most sufferers also sleep for longer than they realize, and sleep-restriction therapy can actually be useful in treating severe depression.

Worsening Green's plight are the questionable exhortations that we live in a sleepless society riven with 'sleep debt'. Deprived sleepers supposedly run the risk of obesity, developing metabolic syndrome (a combination of risk factors associated with increased cardiovascular disease, liver disease and type 2 diabetes) or worse. This idea is based on old and often misquoted arguments that our grandparents got, on average, nine hours of sleep every night, so we should do the same. This number is flawed. The original research was carried out 100 years ago and focused on school children, not adults. Since the 1960s, findings from the United Kingdom have shown that the average daily sleep has remained consistent at around seven-and-aquarter hours.

Recent claims that inadequate sleep causes obesity mostly come from over-generalized laboratory and epidemiological findings. Acute sleep restriction - for example, four hours daily over six days - may produce metabolic changes, but few people can cope with so little sleep and the profound sleepiness that results. Even enduring less than five hours sleep a night for many years would result in only modest weight gain, on average about 1 kilogram per year. Insomniacs usually sleep more than this. Proving the possible corollary that one might lose weight by extending sleep would probably take years to accomplish; contrast this with the rapid effectiveness of exercise and diet.

Maybe Green should pause to be thankful about her life, her writing ability and even her sleep in her no doubt comfortable bedroom. The typical worker living a century ago would have toiled long hours and gone home to an impoverished, cold, damp and noisy abode, sharing a lumpy bed with the rest of the family, bed-bugs and fleas. Yet he probably slept quite well.

Jim Horne is professor of psychophysiology at Loughborough University, Leicestershire LE11 3TU, UK, and author of Sleepfaring: A Journey Through the Science of Sleep.

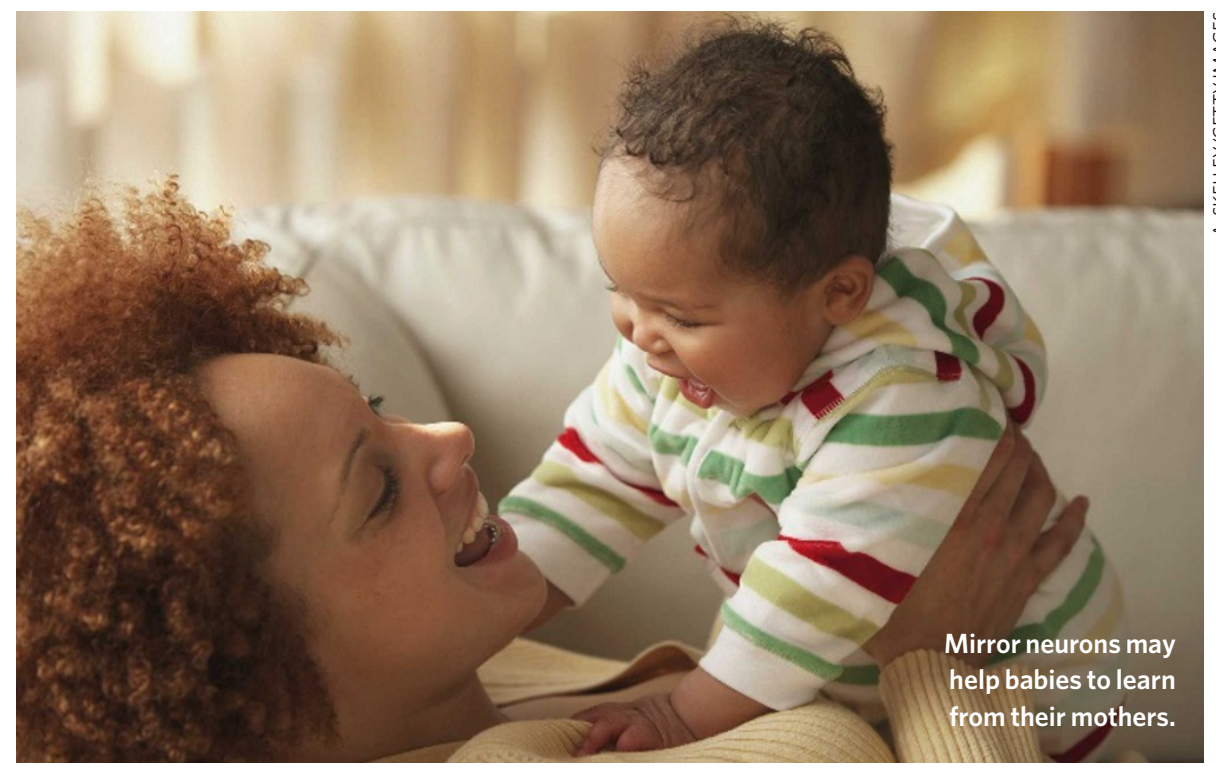

\title{
Reflecting on the mind
}

\section{Mirrors in the Brain}

by Giacomo Rizzolatti and Corrado

Sinigaglia. Translated by Frances

Anderson

Oxford University Press: 2007. 256 pp.

$\$ 49.95$

\section{Vilayanur S. Ramachandran}

When a paradigm-shattering discovery is made in science, it goes through three stages before gaining acceptance. First, people don't believe it; second, they claim it is of no interest; and third, they say that they have always known it. The discovery of mirror neurons in the early 1990s by Giacomo Rizzolatti, Vittorio Gallese, Marco Iacoboni and others, has been through all three stages. Happily, the idea seems to have emerged unscathed, judging from Mirrors in the Brain.

In their readable new book, Rizzolatti and philosopher of science Corrado Sinigaglia survey the growing field that the research has spawned, setting it in historical context. They begin with an overview of the neural circuits in the brain that are involved in simple goaldirected movements. When a monkey reaches for a fruit or puts something in its mouth, motor-command neurons in area F5 in the frontal lobes fire. Different neurons fire for different actions.

Rizzolatti discovered that some of these motor-command neurons fire even when a monkey just watches another monkey performing the same action. He called these cells mirror neurons. They allow one monkey to simulate or imagine another monkey's impending action. Mirror neurons have also been found that fire when a monkey watches another monkey being touched. Another class, canonical neurons, fire both when orchestrating the precise hand and finger movements required to grab a specific object and when one simply looks at that object. It is as if mere readiness to engage in a cylindrical grasp is synonymous - in terms of neural activity - with the perception of a cylinder.

Monitoring mirror-neuron activity might allow us to decipher the computations that lie at the elusive interface between perception and action, providing a key to understanding human cognition. If you extend the definition of action to include more abstract behavioural propensities, you could speak of the cells as representing 'meaning. For example, an apple can conjure many ideas that neural activity may represent differently: it can be reached for and eaten, be used to tempt Eve, can keep the doctor away, go into a pie and so on.

Mirror neurons may be involved in seemingly unrelated mental abilities, such as pretend play in children, imitating skilled actions, emotional empathy and constructing a useful model of another's actions to predict his or her intentions. Because these abilities are lost in autism, it has been suggested that the condition may result partly from mirror-neuron deficiency.

If a mirror neuron fires when someone touches you and when you watch someone being touched, how do you know the difference? One possibility is that when you watch someone else being touched, tactile receptors in your skin inform the regular, non-mirror neuron cells in your brain that they are not being touched, which inhibits the output of your mirror neurons. This would explain our observation that people who have had a hand amputated experience touch sensations in their phantom hand when watching another person's intact hand being touched. The absence of signals from the missing hand removes the inhibition, causing the patient to literally experience another person's sensations, dissolving the barrier between self and others. I have dubbed the cells involved here 'Gandhi neurons'. But the 
inhibition of mirror-neuron output by nonmirror neurons isn't perfect even in people with no amputation, as first noted by Charles Darwin. He observed that we tend to unconsciously tense our calf muscles when watching someone getting ready to throw a javelin, for example.

We may have evolved mirror neurons or acquired them by associative learning. To explain the latter, every time the network that a neuron is part of sends a command, you see your hand moving; eventually, as a result of conditioning, the mere appearance of a moving hand (even someone else's) triggers the same neuron. This hypothesis cannot explain why regular, non-mirror, sensory neurons do not also develop such properties through associative conditioning. To explain this, one has to invoke a pre-existing, genetically specified scaffolding that imposes constraints on what is learned.

Infants imitate their mother smiling or sticking out her tongue, implying a mirrorneuron-like computation for translating the visual appearance into the sequence of muscle twitches. Learning cannot be involved because the infant has never seen its own face. It is possible that the infant's smile is just a reflex that doesn't require elaborate translation. This can be ruled out if the newborn can also mimic an asymmetrical smile or a peculiar expression, which demands a sophisticated interfacing between visual appearance and motor output.

Mirror neurons may also have clinical relevance for phantom pain and stroke rehabilitation. If a mirror is propped up vertically on a table in front of a patient with, for example, a paralysed left hand (so that one edge of the mirror is against his chest), the patient gets the illusion that the left hand is moving when he moves his right hand. We and others have found that this causes recovery from paralysis, perhaps by visually reviving dormant mirror neurons.

Mirrors in the Brain documents how this new science has been received. Some psychologists have criticized the idea of mirror neurons as being reductionist. Others think it is a mere metaphor for what psychologists have long called the 'theory of mind module' - the ability of our brains to construct internal models of other people's minds to predict their behaviour. This criticism reveals a fear that neuroscience might displace psychology ('neuron envy'), and a misunderstanding of reductionism. It is a bit like saying that the complementarity of the two strands of DNA is a metaphor for the complementarity of offspring and parent.

Psychological and neural explanations are complementary, not mutually exclusive.
In their book, the authors present a longawaited review of many empirical findings, and discuss the deeper implications of these observations for psychology, cognitive science and psycholinguistics, including language origins. Moreover, they write in a jargon-free style that should be intelligible to all.

There has been a lot of media hype surrounding mirror neurons. The real danger is that too much is explained, not too little. This is inevitable with any new discovery but does not, in itself, vitiate the discovery's intrinsic importance. Nearly a decade ago, I wrote that "mirror neurons will do for psychology what DNA did for biology". It remains to be seen whether they will turn out to be anything as important as that, but as Sherlock Holmes said to Watson: "The game is afoot."

Vilayanur S. Ramachandran is professor and director of the Center for Brain and Cognition, University of California, San Diego, La Jolla, California 92093-0109, USA. He is author of The Emerging Mind: The BBC Reith Lectures.

Correction
Joel Shurkin's review of Internet Alley by Paul E.
Ceruzzi (Nature 452,533; 2008) wrongly
asserted that the book lacks an index; in fact, it
does have one.

\section{EXHIBITION \\ Design crystallized in the 1950s}

Colin Martin

In the 1950s, the booming science of X-ray crystallography inspired designers as well as scientists to ponder the structures of nature. The exhibition From Atoms to Patterns: Crystal Structure Designs from the 1951 Festival of Britain at the Wellcome Collection in London explores how these two groups collaborated to bring molecular patterns into our homes.

Crystallographer Helen Megaw saw artistic possibilities for using the patterns generated by X-ray crystallography in wallpapers and fabrics. As a wedding gift for biochemist Dorothy Hodgkin in 1937, she embroidered a design based on the structure of aluminium hydroxide onto a cushion. Megaw thought that "the combination of really attractive pattern with the assurance of scientific accuracy would win a lot of attention".

While planning for the Festival of Britain - a morale-raising national exhibition in London after the Second World War - in the summer of 1951, Mark Hartland Thomas at the Council of Industrial

Design welcomed Megaw's idea. He persuaded 28 British manufacturers, including Dunlop, Wedgwood and the chemical company ICI to join the Festival Pattern Group (FPG) that produced 80 new designs for textiles, wallpapers, ceramics, glass, metal and plastic.

As the FPG's adviser on crystal structure diagrams, Megaw played a pivotal role. She persuaded eminent crystallographers to participate, including Lawrence Bragg, Max Perutz and John Kendrew as well as Hodgkin. The diagrams on which the designs were based were selected by Megaw, who also advised manufacturers on their interpretation. Atomic structures of minerals (such as afwillite and apophyllite), biological molecules (insulin, haemoglobin) and synthetic polymers were incorporated.

At the Festival of Britain, the science of X-ray crystallography featured in displays at the Dome of Discovery on London's South Bank and the Exhibition of Science at the Science Museum. The museum used FPG furnishings - its cinema foyer walls were covered with insulin wallpaper (pictured) and

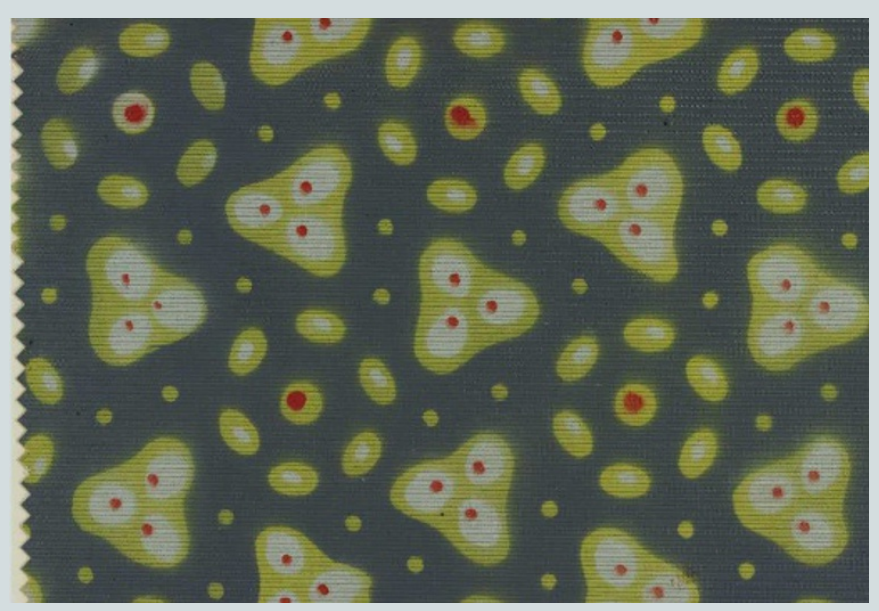

the benches were upholstered in myoglobin leathercloth.

More FPG furnishings decorated the Regatta Restaurant on the South Bank. Diners walked on carpets patterned with resorcinol, gazed at afwillite curtains and haemoglobin laminates, and were served by waitresses whose uniforms had hydrargillitepatterned lace collars. They stubbed out their cigarettes in pentaerythritol glass ashtrays, and used lavatories fitted with apophyllite glass screens.

Writing of the FPG's success, Hartland Thomas observed that the fresh and original designs "were essentially modern because the technique that constructed them was quite recent, and yet, like all successful decoration of the past, they derived from nature - although it was nature at a submicroscopic scale not previously revealed."

Colin Martin is a writer based in London.

From Atoms to Patterns: Crystal Structure Designs From the 1951 Festival of Britain runs at the Wellcome Collection, London, from 24 April to 10 August (www.wellcomecollection.org). 